Article

\title{
Impact of Particle Size Distribution of Colloidal Particles on Contaminant Transport in Porous Media
}

\author{
Jongmuk Won ${ }^{1}\left(\mathbb{D}\right.$, Dongseop Lee ${ }^{2}$, Khanh Pham ${ }^{2}$, Hyobum Lee ${ }^{2}\left(\mathbb{D}\right.$ and Hangseok Choi ${ }^{2, *(1)}$ \\ 1 Department of Civil and Environmental Engineering, University of Ulsan, Daehak-ro 93, Nam-gu, \\ Ulsan 680-749, Korea; jmwon@ulsan.ac.kr \\ 2 School of Civil, Environmental and Architectural Engineering, Anam-dong 5-ga, Korea University, \\ Seoul 136-713, Korea; steallady@korea.ac.kr (D.L.); khanhpnl199@korea.ac.kr (K.P.); \\ lhb6376@korea.ac.kr (H.L.) \\ * Correspondence: hchoi2@korea.ac.kr; Tel.: +82-2-3290-3326; Fax: +82-2-928-7656
}

Received: 25 December 2018; Accepted: 27 February 2019; Published: 5 March 2019

\begin{abstract}
The presence of retained colloidal particles causes the retardation of contaminant transport when the contaminant is favorably adsorbed to colloidal particles. Although the particle size distribution affects the retention behavior of colloidal particles, the impact of particle size distribution on contaminant transport has not been reported to date. This study investigates the impact of the particle size distribution of the colloidal particles on contaminant transport through numerical simulation by representing the particle size distribution as a lognormal distribution function. In addition, the bed efficiency and contaminant saturation of simulated breakthrough curves were calculated, and a contaminant transport model with the Langmuir isotherm for the reaction between the contaminant-sand and contaminant-colloidal particle was introduced and validated with experimental data. The simulated breakthrough curves, bed efficiency, and contaminant saturation indicated that an increase in the mean and standard deviation of the particle size distribution causes the retardation of contaminant transport.
\end{abstract}

Keywords: particle size distribution; colloidal particle; contaminant transport; median particle size; standard deviation

\section{Introduction}

It is now well-known that the transport and retention behavior of organic and inorganic colloidal particles $(<10 \mu \mathrm{m})$ in porous media facilitates or retards contaminant transport when the contaminant is favorably adsorbed to colloidal particles [1-3]. Recent field and laboratory studies demonstrated that even a small amount of colloidal particles lead to the facilitation and retardation of contaminants such as radionuclides (e.g., ${ }^{137} \mathrm{Cs}$ and ${ }^{239} \mathrm{Pu}$ ) or heavy metals (Pb(II) and $\mathrm{Ni}(\mathrm{II})$ ) [4-6]. Therefore, the presence of colloidal particles as well as the transport behavior of colloidal particles should be taken into account in order to properly predict the contaminant transport. This would minimize underestimation or overestimation of the travel distance of contaminants [7,8].

Relatively small sizes of colloidal particles and large hydrodynamic forces exerted upon them cause the particles to be transported rather than retained, leading to the facilitation of contaminant transport. In contrast, if a relatively large number of colloidal particles are retained and not mobile, contaminants are more likely to be retarded and transport more slowly compared to the pore fluid. In this case, the larger amount of retained colloidal particles leads to the slower transport of contaminant because of more available adsorption sites in colloidal particles-sand media $[9,10]$. Therefore, an accurate estimation of the quantity of immobile colloidal particles cannot be overemphasized for the prediction of contaminant transport. 
In order to predict the amount of immobile colloidal particles, many preceding studies of colloid transport have documented the impact of size ratio between colloidal particles and sand, solution chemistry (ionic strength or $\mathrm{pH}$ ), fluid drag force, and degree of saturation [11-15]. However, the monodisperse latex colloids used in most of these experimental studies cannot represent the polydisperse colloids in subsurface such as clay particles, commonly observed in nature, that contaminant (e.g., heavy metals and radionuclides) are favorably adsorbed. In addition, sand also can be polydisperse, showing a coefficient of uniformity of about 10 [16]. This implies that the particle size distributions of sand and colloidal particles should be considered for the accurate prediction of contaminant transport.

The objective of this study was to numerically investigate the impact of the particle size distributions of sand and colloidal particles on contaminant transport. The breakthrough behavior of contaminant at the given mean and standard deviation of particle size distributions of sand and colloid particles was evaluated and discussed. In addition, the amount of immobile colloidal particles at given particles size distributions was evaluated using the model proposed by Won and Burns (2018) [17]. Consequently, the contaminant saturation and the bed efficiency of particle-retained sand medium were evaluated in order to represent simulated breakthrough curves quantitatively.

\section{Mathematical Model}

\subsection{Colloidal Particle Transport in Saturated Porous Media}

Three main mechanisms can be taken into account for colloidal particle-sand interaction during the transport of particles in saturated porous media: straining, attachment, and detachment [12,18]. Straining is the retention mechanism of particles caused by a relatively large particle size compared to the size of pore space $[19,20]$. Attachment is another retention mechanism of particles induced by the net attraction energy between the colloidal particles and sand, typically explained by the Derjaguin, Landau, Verwey, and Overbeek (DLVO) theory [21,22]. The detachment mechanism represents the separation of retained colloidal particles from sand induced by fluid drag forces $[23,24]$. The one-dimensional continuum scale advection-dispersion-type governing equation with consideration of the above three main mechanisms can be expressed as:

$$
\begin{gathered}
\frac{\partial\left(n C_{c}\right)}{\partial t}=-q \frac{\partial\left(n C_{c}\right)}{\partial z}+\frac{\partial}{\partial z}\left(n D_{c} \frac{\partial C_{c}}{\partial z}\right)-n k_{a t t} \psi_{a t t} C_{c}+\rho_{b} k_{d e t} S_{a t t}-n k_{s t r} \psi_{s t r} C_{c}, \\
\rho_{b} \frac{\partial S_{c}}{\partial t}=n k_{a t t} \psi_{a t t} C_{c}-\rho_{b} k_{d e t} S_{a t t}+n k_{s t r} \psi_{s t r} C_{c},
\end{gathered}
$$

where $n(-)$ is the porosity, $C_{c}\left(\mathrm{M} \mathrm{L}^{-3}\right)$ is the particle concentration in aqueous phases, $\mathrm{t}(\mathrm{T})$ is the time, $q$ $\left(\mathrm{L} \mathrm{T}^{-1}\right)$ is the Darcy's velocity, $z(\mathrm{~L})$ is the depth, $D_{c}\left(\mathrm{~L}^{2} \mathrm{~T}\right)$ is the dispersion coefficient of particles, $\rho_{b}$ is the bulk density of sand $\left(\mathrm{M} \mathrm{L}^{-3}\right)$, and $k_{\text {att }}\left(\mathrm{T}^{-1}\right), k_{\text {det }}\left(\mathrm{T}^{-1}\right)$ and $k_{s t r}\left(\mathrm{~T}^{-1}\right)$ are the first-order coefficients accounting for attachment, detachment, and straining, respectively. $\psi_{\text {att }}$ and $\psi_{s t r}$ are the dimensionless functions for colloidal particle attachment and straining, respectively, and $S_{c}\left(M^{-1}\right)$ is the solid-phase concentration of retained colloidal particles $\left(S_{c}=S_{\text {att }}+S_{\text {str }}\right.$, where $S_{\text {att }}\left(\mathrm{M} \mathrm{M}^{-1}\right)$ and $S_{\text {str }}\left(\mathrm{M} \mathrm{M}^{-1}\right)$ are the solid-phase concentrations of attached and strained colloidal particles). $\psi_{\text {att }}[25,26], \psi_{\text {str }}$ [12], $k_{\text {att }}$ [27], and $k_{s t r}$ [12] in Equation (1) can be expressed as functions of the radius of colloidal particle $\left(r_{c}\right)$ and the radius of sand $\left(r_{s}\right)$ (see details in [17]):

$$
\begin{gathered}
\psi_{a t t}\left(r_{c}, r_{s}\right)=1-\frac{S_{a t t}}{S_{\max }\left(r_{c}, r_{s}\right)}, \\
\psi_{s t r}=\left(\frac{d_{s 50}+z}{d_{s 50}}\right)^{-\beta},
\end{gathered}
$$




$$
\begin{gathered}
k_{s t r}\left(r_{c}, r_{s}\right)=4.495\left(\frac{r_{c}}{r_{s}}\right)^{1.42}, \\
k_{a t t}\left(r_{c}, r_{s}\right)=\frac{3\left(1-\theta_{w}\right)}{2 d_{s 50}} \alpha\left(r_{c}\right) \eta_{0}\left(r_{c}, r_{s}\right) v_{s},
\end{gathered}
$$

where $S_{\max }\left(\mathrm{M} \mathrm{M}^{-1}\right)$ is the maximum attached mass of colloidal particles per unit mass of sand, $d_{s 50}$ $(\mathrm{L})$ is the median size of sand, $\beta(-)$ is a fitting parameter $(\beta=0.43$, see [12]), $\alpha(-)$ is the attachment efficiency, $\eta_{0}(-)$ is the single-collector collision efficiency [28,29], and $v_{S}\left(\mathrm{~L} \mathrm{~T}^{-1}\right)$ is the average seepage velocity. Note that the $S_{\max }$ adopted in this paper was determined by the equation presented in [18], derived from the geometry of spherical colloidal particles and sand.

\subsection{Colloidal-Particle-Associated Contaminant Transport in Saturated Porous Media}

Assuming the all pore space is accessible to colloidal particles (i.e., no dead pores for colloidal particle transport) and colloidal particles are irreversibly retained during contaminant transport (i.e., no detachment), the mass balance equation for the colloidal-particle-associated contaminant transport in saturated porous media can be expressed as $[9,30]$ :

$$
\frac{\partial(n C)}{\partial t}+\rho \frac{\partial S_{e}}{\partial t}+\rho \frac{\partial S_{k}}{\partial t}+\rho \frac{\partial S_{c} S_{i c}}{\partial t}=-q \frac{\partial(n C)}{\partial z}+\frac{\partial}{\partial z}\left(n D \frac{\partial C}{\partial z}\right)
$$

where $C\left(\mathrm{M} \mathrm{L}^{-3}\right)$ is the dissolved contaminant concentration in aqueous phase, $\rho\left(\mathrm{M} \mathrm{L}^{-3}\right)$ is the bulk density of sand medium, $S_{e}\left(\mathrm{M} \mathrm{M}^{-1}\right)$ is the concentration of contaminant sorbed instantaneously to the sand, and $S_{\mathrm{k}}\left(\mathrm{M} \mathrm{M}^{-1}\right)$ is the concentration of contaminant sorbed kinetically to the sand. In addition, $S_{i c}$ $\left(\mathrm{M} \mathrm{M}^{-1}\right)$ is the contaminant sorbed by retained colloidal particles. For three of the time derivative terms on the left-hand side associated with the adsorption of contaminant, the application of the Langmuir isotherm model on the contaminant-sand adsorption and the contaminant-retained colloidal particles adsorption leads to [31]:

$$
\begin{gathered}
\rho \frac{\partial S_{e}}{\partial t}=\rho f K_{1} q_{\max (1)} \frac{\partial C}{\partial t} \\
\rho \frac{\partial S_{k}}{\partial t}=\rho \omega_{1}\left[(1-f) \frac{q_{\max (1)} K_{2} C}{1+K_{2} C}-S_{k}\right], \\
\rho \frac{\partial S_{c} S_{i c}}{\partial t}=\rho \omega_{2}\left[\frac{q_{\max (2)} K_{2} C}{1+K_{2} C} S_{c}-S_{i c} S_{c}\right]+\mathrm{k}_{c} \rho S_{c} S_{i c},
\end{gathered}
$$

where $f(-)$ is the fraction of instantaneously sorbed contaminant in the two-site adsorption model $(f$ was assumed to be 0.01 in this study), $K_{i}\left(\mathrm{~L}^{-3} \mathrm{M}\right)$ is the distribution coefficient of dissolved contaminant to the adsorbent ( $i=1$ for sand, $i=2$ for colloidal particle), $q_{\max (i)}\left(\mathrm{M} \mathrm{M}^{-1}\right)$ is the adsorption capacity, $\omega$ $\left(\mathrm{T}^{-1}\right)$ is the first-order rate constant, and $k_{c}\left(\mathrm{~T}^{-1}\right)$ is the first-order reaction rate constant. The application of the Langmuir isotherm in Equations (8)-(10) keeps the amount of adsorbed contaminant less than $q_{\max }$.

\subsection{Sampling of Colloidal Particles and Sand}

The Latin hypercube sampling (LHCS) method ([32]) was applied for sampling colloidal particles and sand at given particle size distributions. This method provides an even distribution of sample colloidal particles throughout the particle size distribution curve. The particle size distributions are represented by lognormal distribution functions and the mathematical formulation of $m$ th probability values in the LHCS method $\left(P_{m}\right)$ and $m$ th sampled $r_{c}\left(r_{c(m)}\right)$ at the given lognormal distribution function $F$ is given as:

$$
\begin{gathered}
\mathrm{P}_{\mathrm{m}}=\left(\frac{1}{N}\right) u_{m}+\left(\frac{m-1}{N}\right), \\
r_{c(m)}=F^{-1}\left(P_{m}\right),
\end{gathered}
$$


where $m$ is an integer between 1 and $N, N$ is the sampling size, and $u_{m}$ is the random number generated from 0 to 1 ( 0.5 was assumed in this paper for the reproducibility of sampling result). Using Equations (11) and (12) ensures the reflection of particle size distribution to the sampled $r_{c}$ at the given mean $\left(\mu_{c}\right)$ and standard deviation $\left(\sigma_{c}\right)$, which will eventually affect the amount of retained colloidal particles by the calculated $k_{a t t}$ and $k_{s t r}$ as presented in Equations (5) and (6), respectively.

\subsection{Numerical Modeling}

The equation for colloidal particle transport presented in Equation (1) was solved first at the inlet concentration of $5 \mathrm{~g} \mathrm{~L}^{-1}$ for 30 pore volumes (PVs, 1 PV represents the volume of colloidal particle suspension equal to the pore volume of sand medium) of injection. The obtained retention profile of colloidal particles $\left(S_{c}\right.$ in Equation (2)) was applied to the initial retained colloidal particles for solving the contaminant transport equation (Equation (7)). An inlet contaminant concentration of $5 \mathrm{mg} \mathrm{L}^{-1}$ was applied to the boundary condition for $30 \mathrm{PVs}$ of injection. All parameters used in simulations were identical, except the mean and the standard deviation of the particle size distribution of colloidal particles. The backward Euler method was used for discretizing the governing equations, and the Picard iteration $[33,34]$ was implemented in the model for the convergence in each time step. The dimension of the sand medium domain in all the numerical simulations was set to $30.48 \mathrm{~cm}$ (=1 foot) long, except the model validation (the dimension of domain $=4.61 \mathrm{~cm}$ ). All parameters adopted in the numerical simulation are summarized in Table 1.

Table 1. Parameters adopted in numerical simulation.

\begin{tabular}{ccr}
\hline Parameters & Value & Note and Related Reference \\
\hline$n$ & 0.365 & Updated every time step. Decreased over time as colloidal particles retained \\
\hline$N$ & 1 or 100 & $N=100$ when $\sigma_{c}>0$ \\
\hline$D_{c}\left(10^{-3} \mathrm{~cm}^{2} \mathrm{~s}^{-1}\right)$ & $6.1-6.4$ & Calculated using equations proposed in [35], mean value was used if $N>1$ \\
\hline$D\left(10^{-3} \mathrm{~cm}^{2} \mathrm{~s}^{-1}\right)$ & 2.9 & Experimentally obtained using non-reactive tracer (bromide) \\
\hline$q\left(\mathrm{~cm} \mathrm{~s}^{-1}\right)$ & 0.0123 & - \\
\hline$\rho_{b}\left(\mathrm{~g} \mathrm{~cm}^{-3}\right)$ & 1.68 & The specific gravity of sand was assumed 2.65 \\
\hline$d_{s 50}(\mathrm{~cm})$ & 0.072 & Typical median size of coarse sand \\
\hline$\mu_{\mathrm{c}}$ & $0.1-2$ & Typical median size of clay colloidal particles $\left(r_{c 50}=\mathrm{e}^{\mu}\right)$ \\
\hline$\sigma_{\mathrm{c}}$ & -2.3 to 0.69 & Equivalent to the coefficient of uniformity ranged from 0 to 10 \\
\hline$f(-)$ & 0.01 & Assumed value ([36]) \\
\hline$K_{1}, K_{2}\left(10^{-3} \mathrm{~L} \mathrm{mg}^{-1}\right)$ & $2.202,6.102$ & Obtained by batch experiment ([9]) \\
\hline$q_{\max (1), q_{\max (2)}\left(\mathrm{mg} \mathrm{g}^{-1}\right)} 1.081 \times 10^{-3}, 2.854$ & Obtained by batch experiment ([9]) \\
\hline$\omega_{1}$ & $1.859 \times 10^{-3}$ & Obtained by batch experiment ([9])
\end{tabular}

\subsection{Bed Efficiency and Contaminant Saturation}

The evaluation of breakthrough curves of contaminant allows the qualitative description of contaminant transport at varied $\mu_{c}$ and $\sigma_{c}$. However, obtaining the bed efficiency $(\beta)$ and the contaminant saturation $(\theta)$ from the evaluated breakthrough curves provides the quantitative description of breakthrough curves in each condition. The $\beta$ value represents the fraction of adsorbed contaminant during its transport:

$$
\beta=1-\left(\sum_{j=1}^{\frac{P V_{f}}{\lambda}} 0.5 \lambda\left(\left(\frac{C}{C_{0}}\right)_{j}+\left(\frac{C}{C_{0}}\right)_{j+1}\right)\right) / P V_{f},
$$

where $P V_{f}(-)$ is the final elapsed pore volume ( $P V_{f}=30$ in this work), $\lambda(-)$ is the pore volume interval, and $j$ is an order of normalized concentration starting from $0 \mathrm{PV}\left(j=P V_{f} / \lambda+1\right)$, and $\mathrm{C}_{0}\left(\mathrm{M} \mathrm{L}^{-3}\right)$ is 
the inlet concentration of contaminant. On the other hand, $\theta$ quantifies the saturation of bed at $P V_{f}$ (i.e., the fraction of occupied adsorption sites in the bed), expressed as:

$$
\theta=\left(C_{\mathrm{i}} V_{P V} \beta P V_{\mathrm{f}}\right) /\left(\sum_{k=1}^{N} q_{\max (k)} W_{k}\right),
$$

where $V_{P V}\left(\mathrm{~L}^{3}\right)$ is the volume of 1 pore volume calculated by the porosity of the bed, $N$ is the total number of materials $\left(N=2\right.$ in this study), $q_{\max (k)}\left(\mathrm{M} \mathrm{M}^{-1}\right)$ is the maximum adsorption capacity of contaminant, and $W_{k}(\mathrm{M})$ is the weight of the $k$ th material in the bed.

\section{Results and Discussion}

\subsection{Model Validation}

While the equations for contaminant adsorption to sand adopted in this paper (Equations (8) and (9)) have been reported and used in the literature [31,37], the equation describing the adsorption mechanism of contaminant to retained colloidal particles presented in Equation (10) has not been reported. Therefore, the model presented in the previous sections was validated by comparing with laboratory experimental data as follows.

Two cases of the experimental data presented in [9] were selected to validate the model documented in the previous sections and to obtain $\omega_{2}$ and $\mathrm{k}_{\mathrm{c}}$, which describe the adsorption rate of contaminant to retained colloidal particles. A column experiment was performed to investigate the transport of $\mathrm{Pb}(\mathrm{II})$ under the presence of retained kaolinite colloidal particles. The column with $5.08 \mathrm{~cm}$ diameter and $4.61 \mathrm{~cm}$ height was designed and uniformly packed with $1 \%-5 \%$ kaolinite content. After equilibrating the system using the background solution without $\mathrm{Pb}(\mathrm{II}), 5 \mathrm{mg} \mathrm{L}^{-1}$ of $\mathrm{Pb}$ (II) solution was injected for $100 \mathrm{PVs}$. Conditions of the selected experiment cases for the model validation in this paper were $1 \%$ and $5 \%$ of kaolinite content at $6 \mathrm{~mL} \mathrm{~min}^{-1}$ of flow rate and $\mathrm{pH} \sim 6$. Detailed information on the experimental procedure is documented in [9].

The trust-region algorithm was used to obtain the best curve-fitted breakthrough curves and $\omega_{2}$ and $k_{c}$ at given observed breakthrough curves (the step and function tolerance for the stopping criteria was set as $10^{-6}$ ). As seen in Figure 1, the proposed model in this paper simulated the observed breakthrough curves accurately. Even though the back-calculated coefficients in Figure 1 may be able to exclusively describe the $\mathrm{Pb}(\mathrm{II})$ transport under the presence of kaolinite, the values of $\omega_{2}=0.016 \mathrm{~s}^{-1}$ and $k_{c}=0.0152 \mathrm{~s}^{-1}$ were used in further simulation in order to investigate the impact of $\mu_{c}$ and $\sigma_{c}$ of particle size distribution on contaminant transport at given $\omega_{2}$ and $k_{c}$.

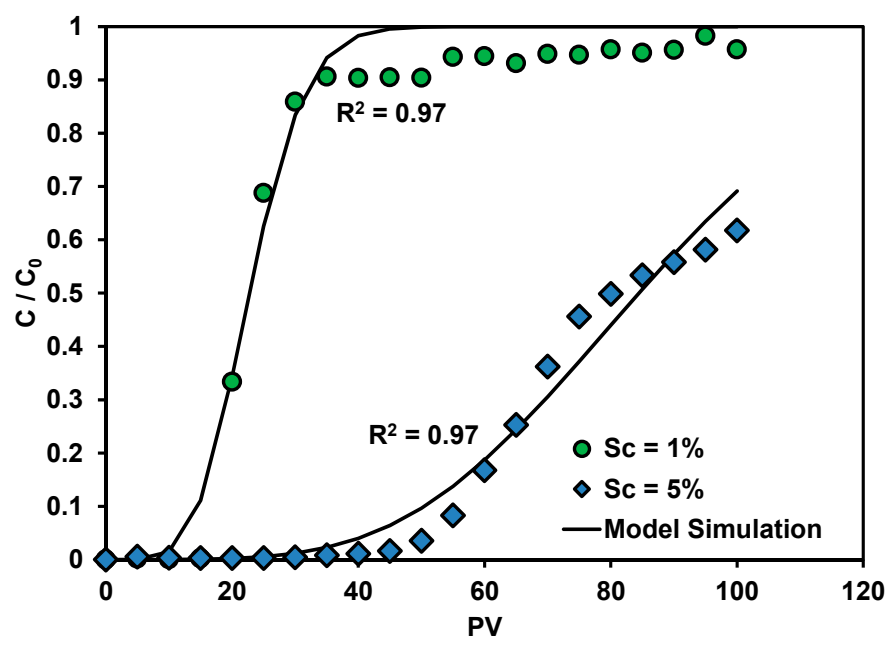

Figure 1. Observed and modeled breakthrough curves of $\mathrm{Pb}$ (II) under the presence of retained kaolinite colloidal particles at $1 \%$ and $5 \%$. Back-calculated $\omega_{2}$ and $k_{c}$ are also presented with $\mathrm{R}^{2}$ values. PV: pore volume. 


\subsection{Impact of Median Colloidal Particle Size $\left(r_{c}\right)$}

Figures 2 and 3 illustrate the contaminant breakthrough curves and the retention profile of colloidal particles at $r_{c}=0.1,0.5,1$, and $2 \mu \mathrm{m}$. While Figure 2 shows the concentration of contaminant at the outlet of the sand medium during the injection, Figure 3 presents the amount of retained particles with depth after injecting 30 pore volumes of particle suspension. As seen in Figure 2, the transport of contaminant was retarded when $r_{c}$ increased because of a more significant amount of retained colloidal particles at higher $r_{c}$ as illustrated in Figure 3. The higher value of $r_{c}$ led to greater $k_{a t t}$ and $k_{s t r}$ in Equation (1) as presented in Figure 4 (except $r_{c}<0.4 \mu \mathrm{m}$ because of large $\eta_{0}$ value at relatively low $r_{c}$, see details in [29]), which resulted in a larger amount of retained colloidal particles. It can be anticipated that increases in the number of retained colloidal particles would correspond to slower the contaminant transport at the given adsorption rate. The results presented in Figure 2 imply that the size of the colloidal particles should be taken into account as one of the critical parameters in contaminant transport through porous media. That is, a slight increase in $r_{c}$ can retard the contaminant transport significantly. The retardation of transport would be more substantial if $\omega_{2}$ and $k_{c}$ were larger than the values considered in this paper.

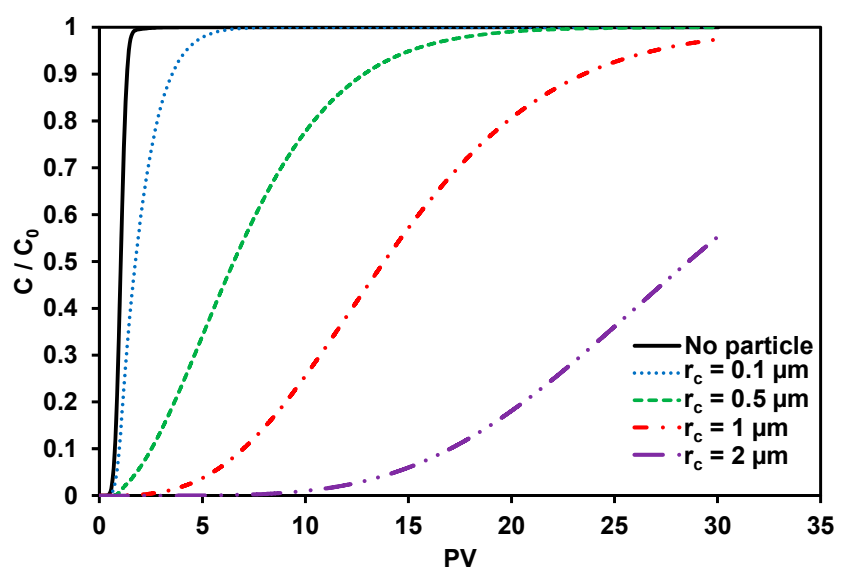

Figure 2. Simulated breakthrough curves of the contaminant at inlet colloidal particle sizes ranging from 0.1 to $2 \mu \mathrm{m}$.

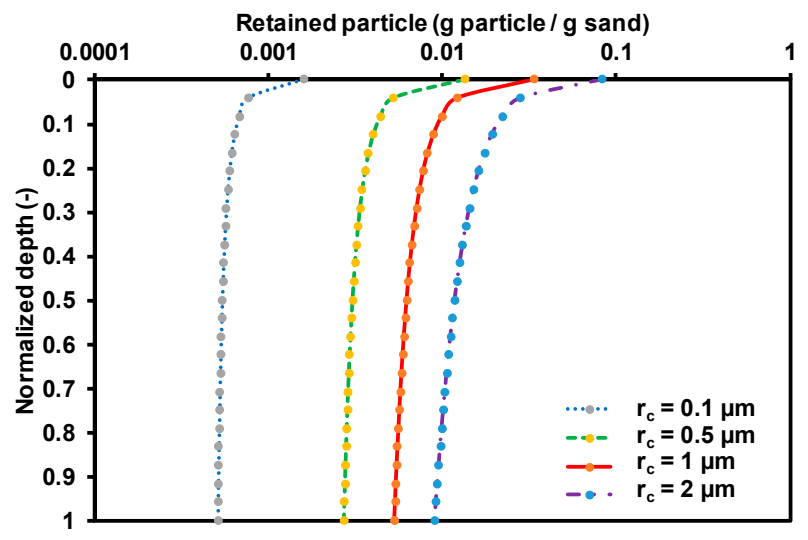

Figure 3. Simulated retention profiles of colloidal particles at in inlet colloidal particle sizes ranging from 0.1 to $2 \mu \mathrm{m}$. 


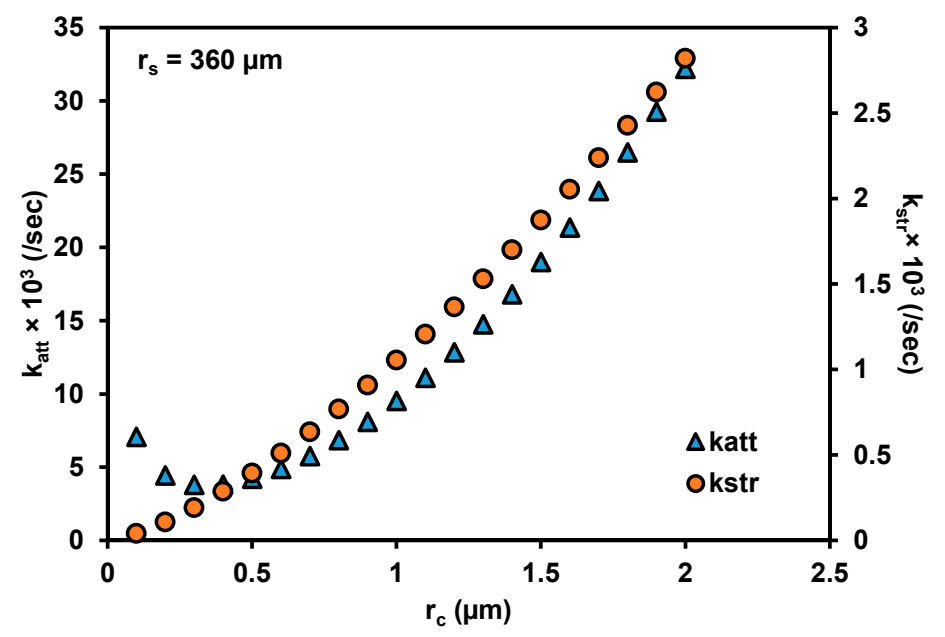

Figure 4. Calculated $k_{\text {att }}$ and $k_{s t r}$ using Equations (5) and (6) at varied $r_{c}\left(0.1 \mu \mathrm{m}\right.$ interval) and $r_{s}=360 \mu \mathrm{m}$.

\subsection{Impact of the Standard Deviation of the Particle Size Distribution of Colloidal Particles}

The median particle radii of 0.18 and $0.55 \mu \mathrm{m}$ were selected, which correspond to the median particle diameter of kaolinite SA1 and kaolinite RP2 in [38], in order to investigate the impact of the standard deviation of particle size distribution. Figure 5 illustrates simulated breakthrough curves of contaminants and the retention profiles of particles at varied $\sigma_{c}$ and $\mu_{c}=-1.72$ (corresponding to the median particle size $=0.18 \mu \mathrm{m}$ ). It is clearly observed that the increase in the standard deviation of particle size distribution (i.e., an increase in the coefficient of uniformity) retarded the transport of contaminant (Figure 5a). This is attributed to the larger amount of retained particles at higher $\sigma_{c}$ (Figure $5 \mathrm{~b}$ ), which is caused by larger values of sample $r_{c}$ at higher $\sigma_{c}$ (Figure 6). As presented in [17], in the identical median size, the amount of retained particles increased as $\sigma_{c}$ increased. In other words, no consideration of $\sigma_{c}$ in colloidal particle transport in porous media would lead to a significant underestimation of the amount of retained particles. The results obtained in Figure 5 indicate that $\sigma_{c}$ can be a critical factor not only for the colloidal particle transport but also for the contaminant transport when the contaminants are favorably adsorbed to retained colloidal particles.

The impact of $\sigma_{c}$ became more significant when $\mu_{\mathrm{c}}$ increased, as demonstrated in Figure 7. At $\mu_{\mathrm{c}}$ $=-0.6$ (corresponding to the median particle size of $0.55 \mu \mathrm{m}$ ), the retardation of contaminant transport was more significant compared to the case of $\mu_{c}=-1.72$, as illustrated in Figure 7a. This result may be explained mainly by the fact that an increase in the amount of strained particles due to increasing $\sigma_{\mathrm{c}}$ is greater at larger $\mu_{c}$ (showing a more exponential retention profile according to $\sigma_{c}$ at $\mu_{c}=-0.6$ (Figure $7 \mathrm{~b}$ ) than at $\mu_{c}=-1.72$ (Figure $5 \mathrm{~b}$ ). The significant increase in retained particles at the top layer of the sand medium corresponding to the increase of $\sigma_{c}$ provided a large number of adsorption sites at the top layer, which resulted in the significant retardation of contaminant transport. 

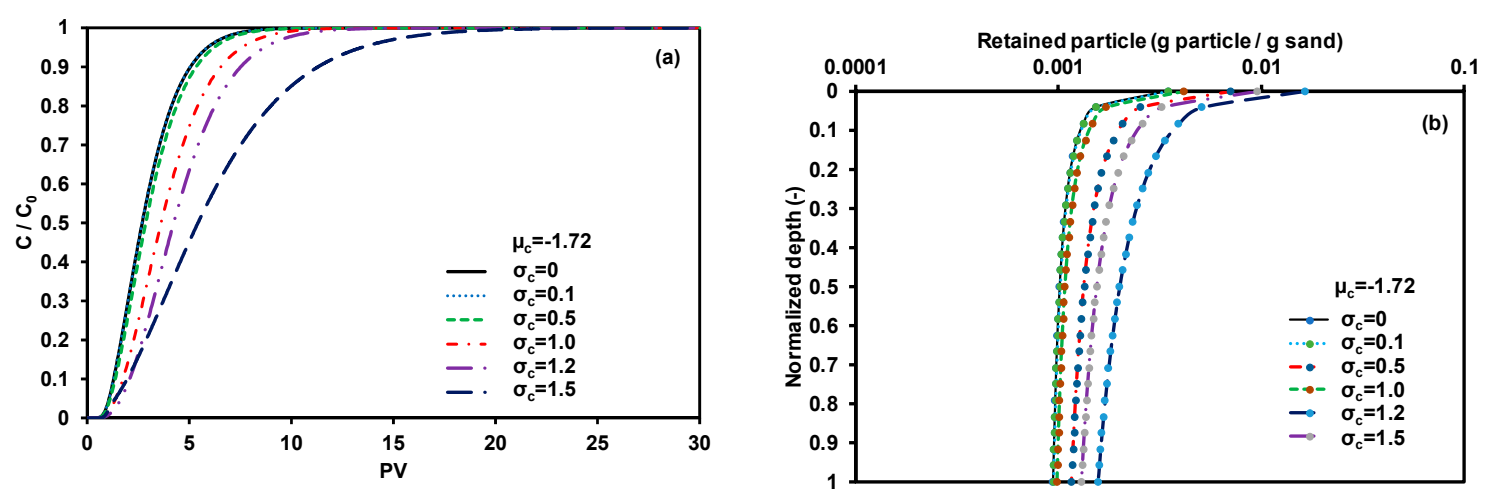

Figure 5. (a) Simulated breakthrough curves of contaminant and (b) the retention profiles of particles at $\mu_{c}=-1.72$ and $\sigma_{c}=0,0.1,0.2,1.0,1.2$, and 1.5 .

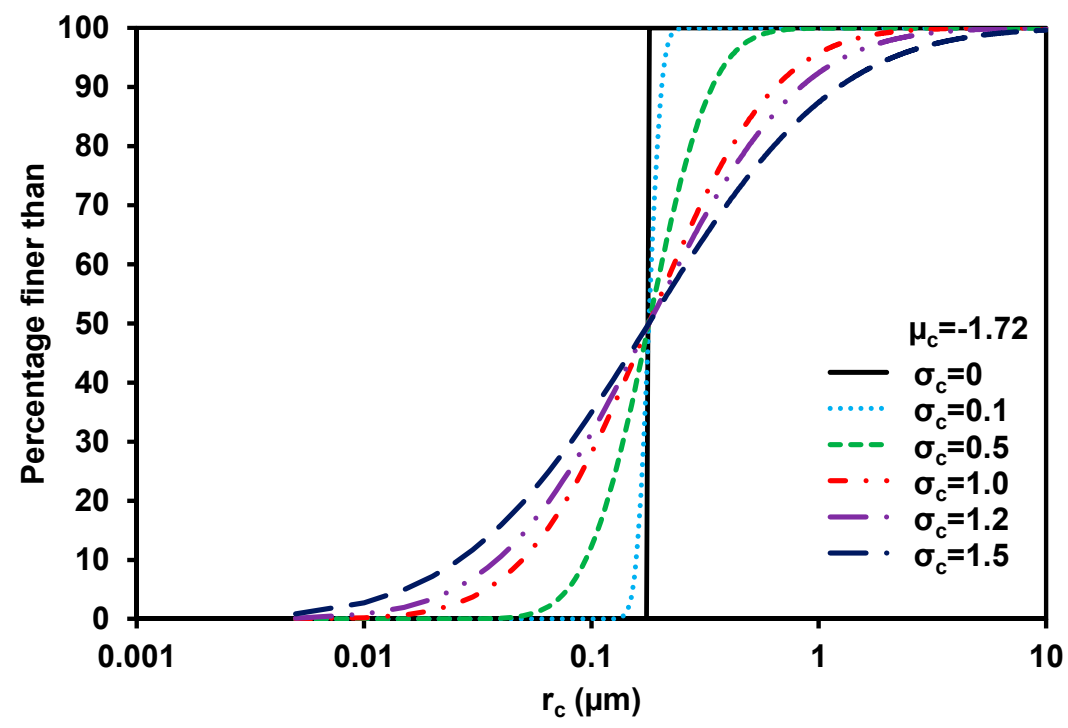

Figure 6. Particle size distributions for colloidal particles $\left(\mu_{c}=-1.72\right)$ used in the simulation.
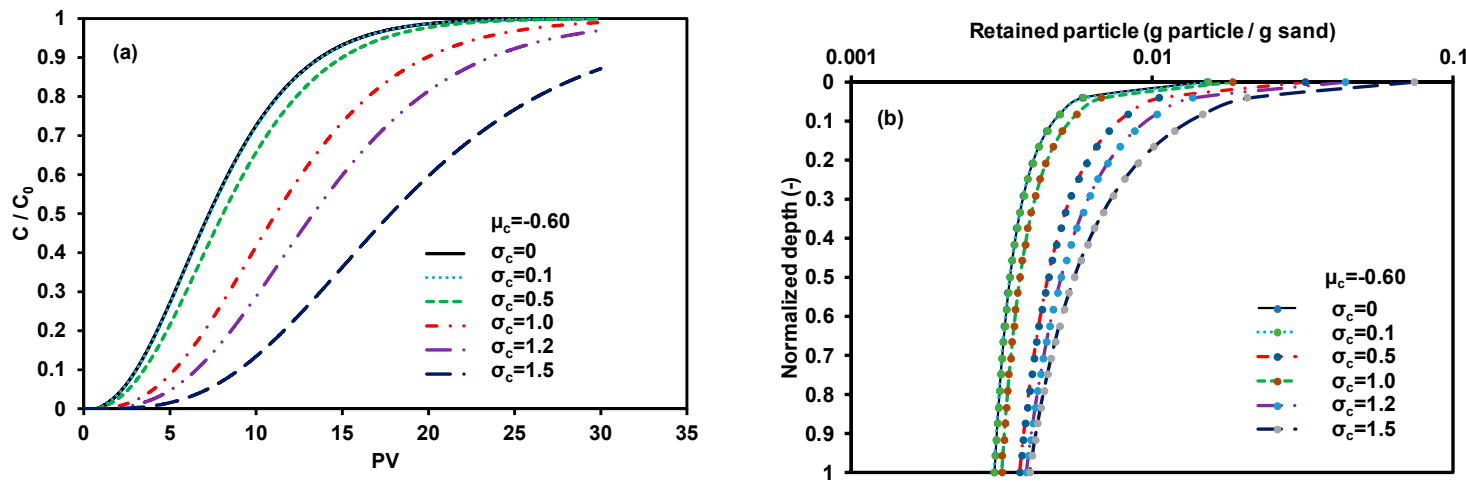

Figure 7. (a) Simulated breakthrough curves of contaminant and (b) the retention profiles of particles at $\mu_{c}=-0.60$ and $\sigma_{\mathcal{c}}=0,0.1,0.2,1.0,1.2$, and 1.5 .

\subsection{Bed Efficiency and Contaminant Saturation}

Figures 8 and 9 illustrate the calculated $\beta$ and $\theta$ using Equations (13) and (14) for Figure 2, Figure 5a, and Figure $7 \mathrm{~b}$. The value of $\beta$ almost linearly increased as $r_{c}$ increased because of the retardation of contaminant transport, while $\theta$ decreased as $r_{c}$ increased, caused by the increase in retained colloidal particles. Forty percent of available adsorption sites $(\theta \sim 0.6)$ in the bed at $r_{c}=2 \mu \mathrm{m}$ after $30 \mathrm{PV}$ of contaminant injection implies that the increase in adsorption sites affects the long-term 
transport behavior of contaminants as well as the retardation of transport. In addition, the evaluation of $\beta$ provides the threshold $r_{c}$ at which the contaminant is not detected at the outlet after the given PVs. For instance, the extrapolation of $\beta$ values presented in Figure 8 indicates that the contaminant would not be detected during $30 \mathrm{PV}$ of injection at $r_{c}>2.3 \mu \mathrm{m}$ (i.e., $\beta=1$ at $r_{c} \sim 2.3 \mu \mathrm{m}$ ).

In contrast, the increase in $\sigma_{c}$ led to an increase in $\beta$ and $\theta$ at $\mu_{c}=-1.72$ and -0.6 . However, while $\beta$ increased significantly as $\sigma_{c}$ increased, a slight increase in $\theta$ was observed at $\mu_{c}=-0.6$. This implies the exponential increase in the adsorption capacity of the bed as $\sigma_{c}$ increases when $\mu_{c}$ is relatively high. In other words, substantial adsorption sites were still available at high $\sigma_{c}$ after the significant retardation of contaminant transport. As stated above, the calculation of $\beta$ and $\theta$ provides the quantitative description of observed/simulated breakthrough curves as well as the prediction of the breakthrough point.

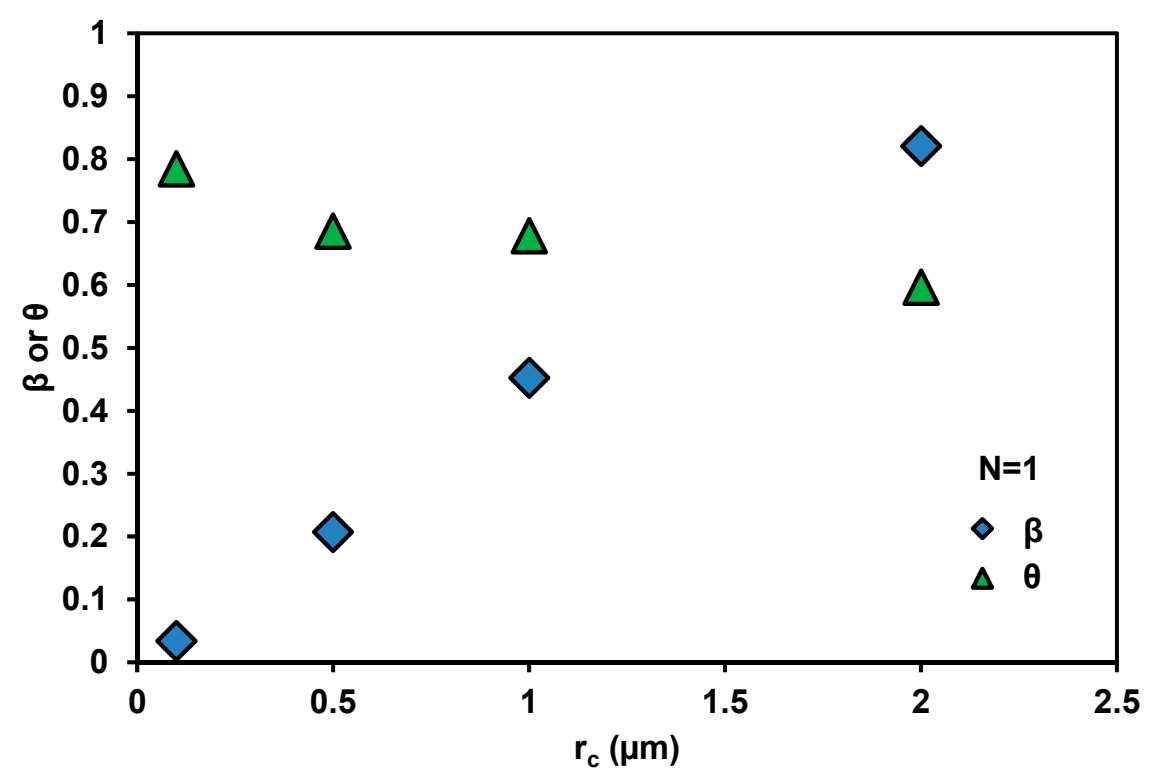

Figure 8. Calculated $\beta$ and $\theta$ for Figure 2.

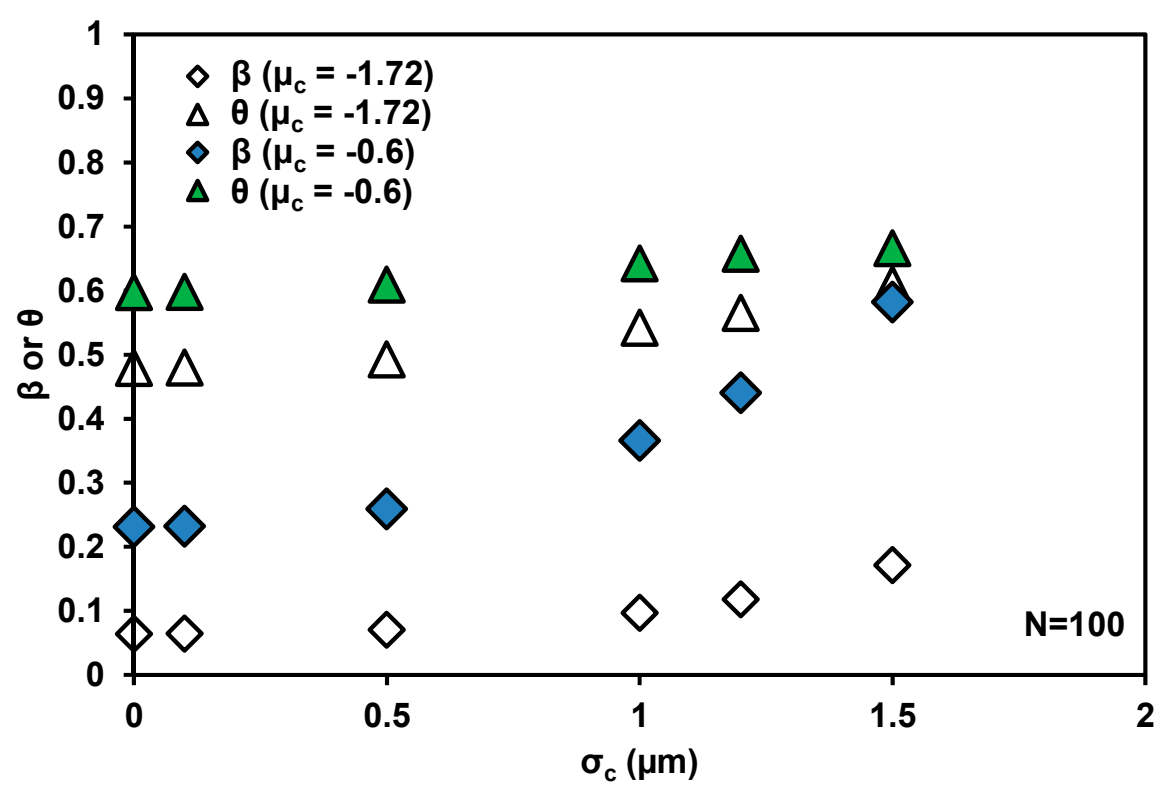

Figure 9. Calculated $\beta$ and $\theta$ for Figures $5 a$ and $7 a$. 


\section{Conclusions}

This work investigated the impact of particle size distribution for colloidal particles on contaminant transport by performing a numerical simulation. The colloidal-particle-associated contaminant transport model along with the Langmuir adsorption model for the reaction between contaminant-sand and contaminant-colloidal particles was introduced, and a parametric study was performed at varied mean and standard deviation of particle size distribution. Based on the observations from simulated breakthrough curves, the key findings can be summarized as follows:

1. The experimental breakthrough curves of $\mathrm{Pb}$ (II) under the presence of retained kaolinite particles were described well by the colloidal-particle-associated contaminant transport model introduced in this paper. This implies that the model can be used for the prediction of transport of heavy metals under the presence of immobile kaolinite particles or other particles that favorably adsorb the heavy metals.

2. As the median size of the colloidal particles and the standard deviation increased, the transport of contaminants was retarded. The impact of a standard deviation on the retardation of transport became more significant as the median size of the colloidal particles increased. This is attributed to the variation in the amount of retained colloidal particles by the median size and the standard deviation of particle size distribution. Therefore, the particle size distribution of particles should be taken into account in the prediction of contaminant transport.

3. A quantitative description of simulated breakthrough curves from the calculated $\beta$ and $\theta$ provides the remaining available adsorption sites of the bed and the prediction of the breakthrough point at a given condition.

4. Further investigation is needed for the impact of particle size distribution on contaminant transport when particle and contaminant transport simultaneously. In addition, the unsaturated flow can also be considered in the modeling work to predict the contaminant transport from the surface to groundwater.

Author Contributions: Writing draft paper, J.W.; Investigation and discussion, J.W., D.L, K.P, H.L; Visualization, H.L; Supervision and editing the manuscript, H.C.

Acknowledgments: The authors appreciate the support partially by the Korea Agency for Infrastructure Technology Advancement under the Ministry of Land, Infrastructure and Transport of the Korean government (No. 18SCIP-B108153-04). The authors also wish to thank the anonymous reviewers for their careful review of the manuscript and valuable comments.

Conflicts of Interest: The authors declare no conflict of interest.

\section{References}

1. McCarthy, J.F.; Zachara, J.M. Subsurface transport of contaminants. Environ. Sci. Technol. 1989, $23,496-502$. [CrossRef]

2. Corapcioglu, M.Y.; Jiang, S. Colloid-facilitated groundwater contaminant transport. Water Resour. Res. 1993, 29, 2215-2226. [CrossRef]

3. Sen, T.; Khilar, K.C. Review on subsurface colloids and colloid-associated contaminant transport in saturated porous media. Adv. Colloid Interface Sci. 2006, 119, 71-96.

4. Kretzschmar, R.; Borkovec, M.; Grolimund, D.; Elimelech, M. Mobile Subsurface Colloids and Their Role in Contaminant Transport. In Advances in Agronomy; Elsevier Inc.: Amsterdam, The Netherlands, 1999; pp. 121-193.

5. Torok, J.; Buckley, L.; Woods, B. The separation of radionuclide migration by solution and particle transport in soil. J. Contam. Hydrol. 1990, 6, 185-203. [CrossRef]

6. Penrose, W.R.; Polzer, W.L.; Essington, E.H.; Nelson, D.M.; Orlandini, K.A. Mobility of plutonium and americium through a shallow aquifer in a semiarid region. Environ. Sci. Technol. 1990, 24, 228-234. [CrossRef] 
7. Grolimund, D.; Borkovec, M.; Barmettler, K.; Sticher, H. Colloid-Facilitated Transport of Strongly Sorbing Contaminants in Natural Porous Media: A Laboratory Column Study. Environ. Sci. Technol. 1996, 30, 3118-3123. [CrossRef]

8. Denaix, L.; Semlali, R.M.; Douay, F. Dissolved and colloidal transport of Cd, Pb, and Zn in a silt loam soil affected by atmospheric industrial deposition. Environ. Pollut. 2001, 114, 29-38. [CrossRef]

9. Won, J.; Burns, S.E. Role of Immobile Kaolinite Colloids in the Transport of Heavy Metals. Environ. Sci. Technol. 2018, 52, 2735-2741. [CrossRef] [PubMed]

10. Sen, T.K.; Mahajan, S.P.; Khilar, K.C. Colloid-Associated contaminant transport in porous media: 1. Experimental studies. AIChE J. 2002, 48, 2366-2374. [CrossRef]

11. Bradford, S.A.; Torkzaban, S.; Shapiro, A. A Theoretical Analysis of Colloid Attachment and Straining in Chemically Heterogeneous Porous Media. Langmuir 2013, 29, 6944-6952. [CrossRef] [PubMed]

12. Bradford, S.A.; Simunek, J.; Bettahar, M.; van Genuchten, M.T.; Yates, S.R. Modeling Colloid Attachment, Straining, and Exclusion in Saturated Porous Media. Environ. Sci. Technol. 2003, 37, 2242-2250. [CrossRef] [PubMed]

13. Elimelech, M.; O'Melia, C.R. Kinetics of deposition of colloidal particles in porous media. Environ. Sci. Technol. 1990, 24, 1528-1536. [CrossRef]

14. Xu, S.; Gao, B.; Saiers, J.E. Straining of colloidal particles in saturated porous media. Water Resour. Res. 2006, 42. [CrossRef]

15. Lenhart, J.J.; Saiers, J.E. Transport of Silica Colloids through Unsaturated Porous Media: Experimental Results and Model Comparisons. Environ. Sci. Technol. 2002, 36, 769-777. [CrossRef] [PubMed]

16. Mitchell, J.K.; Soga, K. Fundamentals of Soil Behavior, 3rd ed.; John Wiley and Sons, Inc.: Hoboken, NJ, USA, 2005.

17. Won, J.; Burns, S.E. Stochastic Modeling of Kaolinite Transport through a Sand Filter. Can. Geotech. J. 2018. cgj-2018-0394. [CrossRef]

18. Won, J.; Burns, S.E. Influence of Ionic Strength on Clay Particle Deposition and Hydraulic Conductivity of a Sand Medium. J. Geotech. Geoenvironmental Eng. 2017, 143, 04017081. [CrossRef]

19. Xu, S.; Saiers, J.E. Colloid straining within water-saturated porous media: Effects of colloid size nonuniformity. Water Resour. Res. 2009, 45. [CrossRef]

20. Bradford, S.A.; Simunek, J.; Bettahar, M.; van Genuchten, M.T.; Yates, S.R. Significance of straining in colloid deposition: Evidence and implications. Water Resour. Res. 2006, 42. [CrossRef]

21. Derjaguin, B.V.; Landau, L.D. Theory of the stability of strongly charged lyophobic sols and the adhesion of strongly charged particles in solutions of electrolytes. Acta Physicochim. USSR 1941, 14, 633-662. [CrossRef]

22. Verwey, E.J.W.; Overbeek, J.T.G. Theory of the Stability of Lyophobic Colloids; Elsevier: Amsterdam, The Netherlands, 1948.

23. Bergendahl, J.; Grasso, D. Mechanistic Basis for Particle Detachment from Granular Media. Environ. Sci. Technol. 2003, 37, 2317-2322. [CrossRef] [PubMed]

24. Bergendahl, J.; Grasso, D. Prediction of colloid detachment in a model porous media: Thermodynamics. AIChE J. 1999, 45, 475-484. [CrossRef]

25. Treumann, S.; Torkzaban, S.; Bradford, S.A.; Visalakshan, R.M.; Page, D. An explanation for differences in the process of colloid adsorption in batch and column studies. J. Contam. Hydrol. 2014, 164, 219-229. [CrossRef] [PubMed]

26. Sun, Y.; Gao, B.; Bradford, S.A.; Wu, L.; Chen, H.; Shi, X.; Wu, J. Transport, retention, and size perturbation of graphene oxide in saturated porous media: Effects of input concentration and grain size. Water Res. 2015, 68, 24-33. [CrossRef] [PubMed]

27. Raychoudhury, T.; Tufenkji, N.; Ghoshal, S. Straining of polyelectrolyte-stabilized nanoscale zero valent iron particles during transport through granular porous media. Water Res. 2014, 50, 80-89. [CrossRef] [PubMed]

28. Rajagopalan, R.; Tien, C. Trajectory analysis of deep-bed filtration with the sphere-in-cell porous media model. AIChE J. 1976, 22, 523-533. [CrossRef]

29. Tufenkji, N.; Elimelech, M. Correlation Equation for Predicting Single-Collector Efficiency in Physicochemical Filtration in Saturated Porous Media. Environ. Sci. Technol. 2004, 38, 529-536. [CrossRef] [PubMed]

30. Šimůnek, J.; He, C.; Pang, L.; Bradford, S.A. Colloid-Facilitated Solute Transport in Variably Saturated Porous Media. Vadose Zo. J. 2006, 5, 1035. [CrossRef]

31. van Genuchten, M.T.; Wagenet, R.J. Two-Site/Two-Region Models for Pesticide Transport and Degradation: Theoretical Development and Analytical Solutions. Soil Sci. Soc. Am. J. 1989, 53, 1303. [CrossRef] 
32. McKay, M.D.; Beckman, R.J.; Conover, W.J. Comparison of Three Methods for Selecting Values of Input Variables in the Analysis of Output from a Computer Code. Technometrics 1979, 21, 239-245.

33. Celia, M.A.; Bouloutas, E.T.; Zarba, R.L. A general mass-conservative numerical solution for the unsaturated flow equation. Water Resour. Res. 1990, 26, 1483-1496. [CrossRef]

34. Huang, K.; Mohanty, B.P.; Leij, F.J.; van Genuchten, M.T. Solution of the nonlinear transport equation using modified Picard iteration. Adv. Water Resour. 1998, 21, 237-249. [CrossRef]

35. Delgado, J.M.P.Q. Longitudinal and Transverse Dispersion in Porous Media. Chem. Eng. Res. Des. 2007, 85, 1245-1252. [CrossRef]

36. Pang, L.; Šimůnek, J. Evaluation of bacteria-facilitated cadmium transport in gravel columns using the HYDRUS colloid-facilitated solute transport model. Water Resour. Res. 2006, 42. [CrossRef]

37. Schijven, J.F.; Hassanizadeh, S.M.; de Bruin, R.H.A.M. Two-site kinetic modeling of bacteriophages transport through columns of saturated dune sand. J. Contam. Hydrol. 2002, 57, 259-279. [CrossRef]

38. Palomino, A.M.; Burns, S.E.; Santamarina, J.C. Mixtures of fine-grained minerals kaolinite and carbonate grains. Clays Clay Miner. 2008, 56, 599-611. [CrossRef]

(C) 2019 by the authors. Licensee MDPI, Basel, Switzerland. This article is an open access article distributed under the terms and conditions of the Creative Commons Attribution (CC BY) license (http:/ / creativecommons.org/licenses/by/4.0/). 